\title{
The Utilization of ICT in Local Government Units in Social Policy Applications in Greece
}

\author{
Ntaflou Ioannis Ekaterini \\ Social Policy Department, Panteion University of Athens, Athens, Greece
}

\author{
Email address: \\ katentaf@yahoo.gr
}

\section{To cite this article:}

Ntaflou Ioannis Ekaterini. The Utilization of ICT in Local Government Units in Social Policy Applications in Greece. Social Sciences. Vol. 10, No. 3, 2021, pp. 155-159. doi: 10.11648/j.ss.20211003.21

Received: April 23, 2021; Accepted: May 17, 2021; Published: June 30, 2021

\begin{abstract}
Information and Communication Technologies (ICT), Social Policy and Local Government all together interlinked in turmoil of change, deeply transformed the world and our societies. The transition to e-government, concerns horizontal and vertical changes in state structures that promise to give citizens more participative power in public decisions and a better quality of life. The demographic challenge confronts municipalities with the need to address locally, directly, and focused. Using I.C.T.s arises in the context of the need for better health services governance and social policy. The European initiatives on social protection are increasingly seeking information about good practices to support developments in social public services. The social public services are provided directly to citizens trying to meet their needs at home. This is especially important for people who have been marginalized or somehow excluded from society because of their age or state of their physical disability. These people usually have multiple needs that require a more coordinated and integrated response from services. The development of these services is generally organized at national, regional, or local level. However, many questions about the quality of these services need to be responded. In recent years it has been recognized that the service delivery processes as a commodity must ensure certain standards. The doctoral thesis examines the social service improvements designed to meet the needs of the elderly and disabled service users through the development of geographically focused local and specialized health services. The combination of these trends leads to the formation of a specific model of Social Policy with the use of ICT.s in the research municipalities. As the exemplary local government units, (the municipality of Dodonis and municipality of Central Tzoumerka) in Region of Epirus, Greece, was chosen.
\end{abstract}

Keywords: Social Policy, Local Government, Information and Communication Technologies

\section{Introduction}

The dissertation examines the problem of citizens' access to social policy and health structures [1], which are significantly related to their place of residence and their privileged or unprivileged geographical location. Difficult or impossible access to health services and social policy is a form of social exclusion [2] that puts human survival at immediate risk, especially in isolated and inaccessible environments. It is a phenomenon of discrimination, which has several [3] and spatial characteristics, significantly linked to the effects of place of residence and other social, institutional and individual factors.

The dissertation is structured on the basis of three dimensions that complement each other. First, in the dimension of the theoretical correlation of social policy with that of the local welfare state and space. An effort is being made to record and critically approach the legislative and functional integration of local authorities, which includes its legitimacy in social policy. As a result, specific issues of its implementation arise, under the influence of European policies, but also concerns about the adaptations of local authorities under the pressure of the financial crisis. Second, in the dimension of the critical review of the policies of the electronic and digital adaptation [4, 5] of the local authorities. Third, in the dimension of the empirical investigation of the problem area in achieving access to health services and social policy. In particular, the research was conducted in remote and inaccessible municipalities of the Epirus Region that are known for the sparsely populated area but also for the high percentages of elderly and disabled population. The summary analysis of these three dimensions 
is presented below.

\section{Methodology}

\subsection{Place and Social Policy: Theoretical Relationships}

The theoretical correlation of a place with the social policy is based on the secondary elaboration of scientific studies and a systematic review of international scientific journals. The analysis is attempted in the first four chapters of the dissertation. It seeks to capture the main scientific debate and the relevant European and national policies regarding the overall review of the role, functions and structure of the state. The relevant research shows that, in an ever-changing international economic and social reality, states try to meet old and new needs by reorganizing many of the levels of intervention at the general and specific levels [6]. In this sense, they review their entire policy in the midst of the global financial crisis, forcing the full institutional development of local authorities, projecting the local as a directly controllable field of application, so with more hope of surviving in this crisis [7].

That is where a more systematic theoretical dialogue that advocates the establishment of social policies and the maintenance of a level of social protection is highlighted [8]. This discussion raises issues related to the redistribution of economic resources and focuses on the rearrangement of social policy in the wider context of social and economic inequalities $[9,10]$.

Close to these policies, localism emerges through the digitisation of government and the process of establishing "Digital Municipalities" in the daily life of the citizen as a process of rationalisation of public administration and an approach of the citizens to the most accessible to them and smaller administrative institution, the municipality. The fundamental question is whether defining geographical boundaries and distances ultimately constitutes delimiting or creating a problem.

However, because the scale of locality is changing in time and administration, the intersecting space of a spatial and social analysis necessarily emerges in the essence of the discussion. In this sense, any technological aspect of social policy locality concerns the ability to offset geographical issues with flexible and adaptable applications. Thus the clarification between geographical boundaries and distances separates the essential from the relative uses of the terms and identifies the need for a discussion concerning the composition of locality within societies.

The unique creation and conception of local phenomena in each place and their composition within the societies or their division allows us to consider the technological interventions (political regulations) that concern the internal and permanent composition of the structures. They are ultimately efforts to strengthen services and clearly meet the expectations of changing the management system with features adapted to local elements.

A consistent policy is the implementation of a decision- making method and the means that make it up. In the perspective of introducing the technological dimension in the support of social policy, the basic expectations concern the way and the place. The "need" of the vulnerable groups of this research is an interpreted concept, suggesting a deficit. It concerns the "subject" of the acceptance of the policies of balancing the need but at the same time the institutions of this action, the municipal services.

\subsection{E-government and Local Authorities}

At this level of investigation, the processing of the (new) administrative model of local authorities has shown that it arises as a result of wider reshuffles. The emphasis on social policy, especially for vulnerable social groups and those marginalised by the social services system, gives local authorities a mediating role between the past structures and functions of the welfare state and a future state of social support.

Social policy, local authority and Information and Communication Technologies (ICT) [11] are the key conceptual categories of this future structure. The question of which of them is more appropriate for the development of a new analytical framework in the local field leads to highlighting the peculiar relationship of these three parameters and their (potential) interaction.

The development of a technological model for the provision and organization of social policy and health services in the context of this dissertation follows the general deepening of European policies in the field. It focuses, however, and is adapted to local characteristics through the search for the characteristics of social policy actions in municipalities with specific geomorphological characteristics $[12,13]$. Important for this modelling of the local social policy is the understanding of the problems of the elderly and the disabled arising as a result of physical and financial weakness, age and the structures that surround them and are influenced by the geography of the place, the municipality. The emergence of a policy proposal resulting from the dissertation concerns a local authority with spatially focused and adapted characteristics, which uses ICT in the field of social policy with the aim of absorbing and reducing the "impact of the place of residence".

This proposal answers the question of what principles future developments should be based on when significant changes occur in relation to an ageing population, new forms of work and family life, and social exclusion. The ability of local authorities to adapt to change and act in a timely manner as a presumption of its credibility policy could be seen as a guarantee of its social adequacy.

The experience so far from the study of the municipalities shows that such a thing is not sufficiently fulfilled. However, there are quantitative and qualitative characteristics of the operational and dynamic capacities [14] of the municipalities that can be utilized. The overall picture of local authority reduction is strengthened by the emergence of an informal social policy [15] focusing on health services from the human resources of the permanent residents of the areas. 
These informal social networks are formed by volunteers in different geo-social contexts and have specific demographic characteristics.

The verification or not of these allegations is attempted in the third part of the dissertation by presenting the findings of the field research.

\subsection{Field Research in Municipalities of the Epirus Region}

The research questions that defined the field research methodology were the following: what is the implementation of social policy and how it relates to the conditions of the space in which the potential user lives? Specifically how existing local authority policies meet the needs of social policy and health. The role of local authority is an administrative issue, not only because of the multitude of responsibilities given to it by legislative interventions but mainly because of their use in the light of the criteria of efficiency, prompt service and timely response.

Another key question of the research was the exclusion of specific groups as it is related to individual characteristics (such as age and disability) and other specific elements, but also in general (place of residence), as well as weaknesses in the management system, which widens the gap of the technological space. Finally, the accessibility of local authority services and their indistinguishable service, for vulnerable and non-vulnerable groups of the population, is a fundamental issue for each municipality and region and how it is completed.

The socio-economic crisis has increased demand for public spending due to shrinking personal spending. This creates a burden for the local authority because it will have to formulate appropriate services (sufficiently staffed, financially viable, compatible with the needs of the local community, close to the citizen, etc.) so that it can meet its difficult role.

The development of social policy through ICT, therefore, concerns two basic assumptions on the part of the state, local authorities and citizens:

The first concerns the belief that the institution must in some effective and direct way be close to the citizen, in any case where there is a declared or implicit need. It concerns, precisely, the consolidation of the strongest and closest relationship between the constituent structures of a society, that is, citizens and institutions.

The second concerns the placement of these structures and their response to the issues of health and necessity that arise with age and/or disability for physical and not only assistance to the people concerned. The common denominator of any such substantial effort by society is, at least in theory, the direction of the effectiveness of health promotion interventions, for the benefit of future efforts.

Sometimes, a universal service is a process of sorting out what is provided and to whom. It is essentially a primary level of prevention that includes procedures to confirm or disprove a diagnosis and much more intensive, but also personalised, services for those at higher risk. The effectiveness and cost-effectiveness of the prevention and intervention service will depend on the final set of services and the ability of the health and social care system to target and limit spending with suggestions and interventions to those who could benefit from them.

In the Greek countryside, the percentage of the elderly and the disabled is important and characterises the composition of the local Greek society in its smallest formation, the village. The elderly and disabled who live there, not only due to age and physical illness but also due to the geomorphological characteristics of the place of residence, face a number of daily problems in meeting their basic needs and the most specialised, such as health and social policy. The external conditions that characterise their field of action make their lives difficult and are a framework of social isolation and potential deprivation, which is examined in the present study. The marginalisation and integration of these vulnerable groups into the social fabric is partial, fragmentary and selective. The ability of the local authority to offer quality services and the possibility of use by these users affects their integration and exclusion.

The research was conducted in two phases. In the first phase, a two-way quantitative survey took place in the municipalities under investigation. The aim was to record both the policies of the municipalities and the experience of the citizens-users (elderly and disabled) of the services. In this regard, the first two questionnaires were completed by the social policy executives of the municipalities and then 100 questionnaires were completed by the elderly and people with special needs who live permanently in the municipalities of the survey. Aiming at the best case study in the second phase, 14 in-depth interviews with social service users followed. The presentation of the empirical results of the qualitative, but also the quantitative research was done in a confrontational context of the two municipalities, but also with the distinction of the dimension of their mountainous and lowland layout in the area which was a basic criterion for the selection of the research.

The research focused on a number of villages that have the characteristics of either the mountain / or the lowland layout and are located at a distance greater than the average of the municipality from the nearest urban centre.

\section{Results}

The integration of geography into the practice of Social Policy requires the choice of a set of measures against the basic "subject of space". The design must have a "subject" i.e. a defined space that has resources, needs, structures and specialized features that adapt each design to local data.

The distance of geographical areas/municipalities is given, and concerns structures, services, and human resources. However, it always refers to natural wholes and human additions that are essentially the place where we live and what surrounds it naturally or after human intervention. In other words, it concerns a socially constructed space. By this logic, the scale of space has a single meaning but is connected to the different means we use, and they change 
depending on the object of our actions.

Both the elderly and the disabled constitute a social group that has increased demands for care and health coverage. The adequacy of the Social Policy measures consists of the needs of the population and the space in which they will be implemented.

The possible low population density, or the corresponding low levels of vehicle ownership, but also the very few public transports, are indicators of the problematic access faced by the populations of decentralised Greek municipalities.

The general impression that these problems are well tolerated is wrong.

The development of the "Crisisinfo-centre" proposed in the dissertation concerns, on the one hand, the achievement of proximity that will reduce the response times of the services, supporting the better supervision and management of the areas. The development of the Crisis info-center supports the formulation of geographic policies (geofare) as a prelude to Social Policies (welfare) with applications and actions based on realistic and geographical features of proximity to the citizen. Its starting point and final perspective is the support of the constitutional operation of the Local Authorities in its unique place each time.

\section{Contribution of the Dissertation to the Scientific Dialogue}

Trying to systematically capture the basic socio-economic and geographical dependencies of vulnerable groups is an ongoing process that emphasises its daily, urgent and changing identity. The dissertation is a first attempt to highlight the values and problems of space, as a field of formation of different dynamics and needs, in isolated and inaccessible environments. A second level is sought to treat health as a claimant in the place of residence and the degree of dependence of the elderly and the disabled is reflected from the place of residence and the weather conditions in search of services.

The dissertation highlights the operational readiness of the local authority, which is problematic. The local authority is in a difficult position to take on responsibilities that it does not have the resources to meet. For this reason, but also because of the general mode of operation of the public administration, in order to design an effective social policy for the entire population, the cooperation of different areas is required. Technology is such a space and under certain conditions, it can contribute to the management of many problems related to age and disability.

Furthermore, the dissertation shows that the value of information in the field of social policy lies in its value to specific consumers. That is why the adoption of a strategy for a local social policy with the use of ICT means setting standards and policies and creating differentiated products. We cannot ignore the fact that the spatial parameters in the exercise of social policy are related to the territorial organisation and the geographical scales as the territorial position of the municipalities and their marking in the space is a challenge both for the needs that arise for the citizens and for the municipal presence itself.

\section{Conclusions}

Accessibility of target groups depending on the geographical unit.

The original research hypothesis that the lowlands are easily accessible has been refuted. The elderly and the disabled living in the lowland villages of both municipalities face major access problems which are largely related to their limited incomes and the readiness/disposition of the administrative mechanism of the Municipality to overcome them. We observe that the geographical barriers and the kilometres distances that the research teams are called upon to cover make their movements difficult to deter any desired movement even if it concerns a health issue.

The desired movements of the elderly and the disabled are done with the help of third parties. These third parties (relatives/villagers) determine - in an informal agreement the context of the purchase of transportation and escort services for the elderly/disabled.

The geographical location of the community provides in this sense two conditions: 1) determines the degree of difficulty of access and service that is increased by the seasonal conditions and the infrastructure of movement and 2) incorporates in the socio-economic characteristics of the socially vulnerable groups an additional negative condition of service.

Social exclusion is complex dynamic and spatial, and it leads to the non-realization of social, health care, or cultural rights or participation within a society. The geographical location of the municipalities determines the presence of the services but also the degree of their service by the respective structures. The general finding is that: The presence of services in the research areas has a multiple nature:

On the one hand, it covers, marginally, the health needs of the population.

On the other hand, the Social Policy depends on and is determined by the pretexts of the local structures for the policy measures but also the small degree of coverage of the population.

The geographical criterion is an important factor in shaping the relevant policies.

The administrative reforms, especially of Law 3852/2010, created in some cases huge municipal units, which failed to ensure the desired results of better management. On the contrary, they seem to have met exactly the opposite expectations, ultimately reducing the people's standard of living.

The increased collectivity in the municipalities works protectively:

Collectivism-volunteering compensates for municipal shortcomings, thus highlighting the problem of its absence.

Paradoxically, the acceptance of the given inability of the municipal services to define the locality and its municipal 
boundaries is accompanied by an argument-based view of the positives of their geographical, selective practice. Bypassing the claim that such an attitude could be the product of micropolitical exploitation, the fundamental question is whether defining geographical boundaries and distances ultimately constitutes demarcation or the creation of a problem? However, because the scale of locality is changing in time and administration, the intersecting space of a spatial and social analysis necessarily emerges in the essence of the discussion. In this sense, any technological aspect of the locality of Social Policies concerns the ability to offset geographical issues with flexible and adaptable applications.

The unique creation and conception of local phenomena in each place and their composition within the societies or their division allow us to consider the technological interventions (political regulations) that concern the internal and permanent composition of the structures. They are ultimately efforts to strengthen services and meet the expectations of changing the management system with features adapted to local elements.

A consistent policy is the implementation of a decisionmaking method and the means that make it up. In the perspective of introducing the technological dimension in the support of Social Policy, the basic expectations concern the way and the place. The "need" of the vulnerable groups of this research is an interpreted concept, suggesting a deficit. It concerns the "subject" of the acceptance of the policies of balancing the need but at the same time the institutions of this action, the municipal service.

\section{References}

[1] Baciu A, Negussie Y, Geller A, et al. 2017, Communities in Action: Pathways to Health Equity. National Academies of Sciences, Engineering, and Medicine; Health and Medicine Division; Board on Population Health and Public Health Practice; Committee on Community-Based Solutions to Promote Health Equity in the United States.

[2] Burchardt T, and Hick R,. 2017, "Inequality and the Capability Approach", Centre for Analysis of Social Exclusion: London School of Economics.

[3] Burholt V, Winter B, Aartsen M, Constantinou C, Dahlberg L, Feliciano V, De Jong Gierveld J, Van Regenmortel S, Waldegrave C. 2020, European Journal of Ageing volume 17, pages 3-19. On behalf of The Working Group on Exclusion from Social Relations, part of the COST-financed Research Network 'Reducing Old-Age Exclusion: Collaborations in Research and Policy' (ROSENet)

[4] de Mello, L. and Ter-Minassian T. 2020, "Digitalisation challenges and opportunities for subnational governments", OECD Working Papers on Fiscal Federalism, No. 31, OECD Publishing, Paris, https://dx.doi.org/10.1787/9582594a-en.

[5] OECD 2019, Decentralisation in the health sector and responsibilities across levels of government - Impact on spending decisions and the budget, 7th Meeting of the OECD Joint Network of Senior Budget and Health Officials, https://www.oecd.org/officialdocuments/publicdisplaydocume ntpdf/?cote $=$ COM/DELSA/GOV(2019)2\&docLanguage=En.

[6] OECD, "Regulatory Policy and Governance: Supporting Economic Growth and Serving the Public Interest," Paris: OECD Publishing, 2011 (from executive summary).

[7] OECD (Forthcoming), Policies for present and future service delivery across territories, OECD Publishing.

[8] Spicker, P, 2021, Welfare States, An introduction to Social Policy, http://spicker.uk/social-policy/wstate.htm, obtained on 16 May 2021.

[9] Piketty, T, 2014, Capital in the Twenty-FirstCentury. Cambridge, Massachusetts: Belknap Press of Harvard University Press, 685 pp.

[10] Garland, D, 2016, The welfare state: a very short introduction, Oxford: Oxford University Press.

[11] Aceto, G, Persico V, Pescapé, A, 2018, The role of Information and Communication Technologies in healthcare: taxonomies, perspectives, and challenges. Journal of Network and Computer Applications, Volume 107, 1 April, Pages 125154.

[12] Whitworth A, (ed.) 2019, Towards a Spatial Social Policy: Bridging the Gap Between Geography and Social Policy, Bristol: Policy Press, pp. 226.

[13] Lloyd C. D., Shuttleworth I. G. and Wong D. W. (ed), 2015, Social-Spatial Segregation. Concepts, Processes and Outcomes. Policy Press.

[14] Carneiro A. 2000, "How does knowledge management influence innovation and competitiveness? Journal of Knowledge Management, Vol. 4, No. 2.

[15] Schwartz, E, Litwin, H, 2018, Social network changes among older Europeans: the role of gender. Eur J Ageing. https://doi.org/10.1007/s10433-017-0454-z 